\title{
Alterations in postural control, gait pattern, and muscle function in diabetes mellitus: does it matter in children and adolescents with type 1 diabetes?
}

Zaburzenia kontroli posturalnej, wzorca chodu i funkcji mięśni w cukrzycy: czy jest to problem u dzieci i młodzieży z cukrzycą typu 1?

\author{
'Jakub Ławnicki, Rita Hansdorfer-Korzon', ${ }^{2}$ Małgorzata Myśliwiec
}

${ }^{1}$ Department of Physical Therapy, Faculty of Health Sciences, Medical University of Gdansk, Poland ${ }^{2}$ Department of Paediatrics, Diabetology, and Endocrinology, Faculty of Medicine, Medical University of Gdansk, Poland

\begin{abstract}
Diabetes mellitus (DM) is associated with chronic microvascular complications such as neuropathy. The most frequent is diabetic peripheral neuropathy (DPN) which is related to chronic disability and decrease in quality of life. Alterations in postural control, gait performance, and muscle function are widely described in the literature. However, the role of other non-neuropathic factors in these alterations remains unclear. Although neuropathy is rather rare in children and adolescents with type 1 DM, there is evidence that early changes and symptoms might have their onset in the early stages of the disease. On the other hand, there is no evidence on functional changes related to neuromuscular status in the paediatric population with type 1 DM.
\end{abstract}

Key words:

diabetes mellitus, postural control, gait, muscle function, children and adolescents.

\section{Streszczenie}

Cukrzyca związana jest z ryzykiem występowania przewlekłych powikłań powiązanych z mikrokrążeniem, takich jak neuropatia. Najczęściej występującą formą jest cukrzycowa neuropatia obwodowa, która wiąże się z przewlekłą niesprawnością i pogorszeniem jakości życia. Zaburzenia kontroli posturalnej, chodu i funkcji mięśni są szeroko opisywane w literaturze, niemniej jednak nie do końca wyjaśniona jest rola innych czynników niezwiązanych z neuropatią. Chociaż neuropatia występuje rzadko u dzieci i młodzieży chorych na cukrzycę typu 1, istnieją dowody, że pierwsze zmiany i objawy mogą pojawiać się na wczesnych etapach choroby. Nie ma jednak żadnych doniesień na temat zmian funkcjonalnych związanych ze stanem układu nerwowo-mięśniowego w populacji pediatrycznej z cukrzycą typu 1.

Słowa kluczowe:

cukrzyca, kontrola posturalna, chód, funkcja mięśni, dzieci i młodzież. 


\section{Introduction}

Diabetes mellitus (DM) is one of the most frequent chronic diseases in the paediatric population. Type 1 diabetes mellitus (T1DM) is the most frequent in children; however, recognition of type 2 diabetes mellitus (T2DM) and genetic forms is increasing [1]. The chronic hyperglycaemia of diabetes is associated with long-term damage, dysfunction, and failure of different organs, especially the eyes, kidneys, nerves, heart, and blood vessels [2]. Diabetes results in irreversible changes in microvasculature of kidneys, retina, and neurons; thus, patients with DM are at high risk of microvascular complications: nephropathy, retinopathy, and neuropathy [3]. Clinically evident microvascular complications are rarely seen among children and adolescents with DM, but there is clear evidence that their pathogenesis and early signs develop during childhood and usually accelerate during puberty [3].

Diabetic peripheral neuropathy (DPN) is a major long-term complication of both type 1 and type 2 diabetes. Clinically evident symptoms of DPN are rather rare in children with DM; however, estimates of the prevalence of DPN in children and adolescents vary widely in the literature and range from $7 \%$ to 57\% [4]. Diabetes-induced alterations in peripheral nervous system are in close correlation with disability - mobility disability and daily activities disability [5]. Alterations in gait pattern, postural control, and muscle function are widely described in the literature. It is known that people with DPN reveal some alterations in postural control, gait performance, and muscle function [6], but the nature of these changes remains unclear. Some authors speculate the role of other non-neuropathic factors in the development of such alterations.

The main purpose of this paper is to present the main changes in postural control and gait pattern - as the indicators of neuromuscular function - in people with DM, which are described in the literature. We also discuss the need of translation of this knowledge to the paediatric population with T1DM.

\section{Postural control}

Postural control requires several mechanisms to align the body with respect to gravity, the support surface, and visual surroundings, and it is aimed to stabilise the centre of mass (COM) of the body relative to its base of support. These mechanisms include postural sway during sensory manipulations in quiet stance, reactive postural control, anticipatory postural adjustment, and dynamic balance [7].

Postural stability in diabetes patients is affected, especially in those with clinical neuropathy. Peripheral sensory neuropathy seems to be the primary factor, but the available evidence does not rule out diabetes per se, other types of neuropathy (central, motor, autonomic), or an inability to exploit fully optical and inertial information about posture [8]. A systematic review of 38 studies revealed that patients with DPN exhibit significant deficit in sensorimotor function, balance, and gait. This is in correlation with deterioration of somatosensory, visual, and vestibular sys- tems [6]. Greater sensorimotor impairment, especially plantar cutaneous insensitivity, is significantly associated with poorer forward reaching ability in patients with diabetes [9]. There is strong evidence that diabetic patients with neuropathy demonstrate a relative deficit in their ability to maintain posture when compared with non-neuropathic diabetic patients and healthy subjects [10]. When comparing the ability to maintain balance between people with T2DM and healthy subjects, Cimbiz and Cakir revealed that DPN disturbs balance especially on the dominant leg [11]. Another study showed greater values of centre of pressure (COP) displacement in anteroposterior and mediolateral directions in elderly people with T2DM and neuropathy when compared with age-matched healthy people. These alterations are not dependent on visual information [12]. People with DPN exhibit balance impairments while level walking and stair negotiation. They have greater COM-COP separation when compared with non-neuropathic diabetes patients and healthy controls, and thus may have higher risk of falls during daily activities [13].

On the other hand, there is also some evidence for postural control alterations in diabetes patients without clinical symptoms of neuropathy. Bonnet and Ray suggested that in people with DPN postural impairments may arise not only from neuropathic changes. They also highlighted the role of visual impairments and changes in postural coordination [14]. Centomo et al. revealed that diabetes per se could have a direct effect on postural control during standing after self-induced forward reaching movement. They assessed non-neuropathic patients with T2DM while performing a forward reaching task. These subjects exhibited some difficulties when regaining their stability after self-initiated reaching task [15]. The ability to detect near-threshold postural perturbations is poorer in mature adults with diabetes when compared with neuropathic diabetes individuals, non-diabetic people with neuropathy, and healthy controls [16]. We found only one study focused on postural control in young people with T1DM. In this study postural stability was measured in youth recreational athletes by using static (one leg standing) and dynamic (single leg hopping course) tests. Results suggest that young individuals with T1DM and no neuropathy have reduced postural stability [17].

There is strong evidence for postural control alterations in diabetes, but the role of diabetic neuropathy, non-neuropathic factors, or both is still unclear. In particular, the role of diabetes per se is not fully explained.

\section{Gait characteristics}

Assessment of gait characteristics in diabetes individuals includes: 1) spatio-temporal parameters (i.e. gait velocity, step length/width, step-cycle length), 2) kinematics (i.e. acceleration), 3) kinetics (i.e. ground reaction forces, joint moments), 4) muscle activity (electromyographic evaluation), and 5) foot pressure [18].

A systematic review of 28 studies of diabetic gait showed agreement that diabetic patients walk more slowly and with greater step variability. They also present more plantar pressure 
and higher peak pressures under the metatarsal heads than healthy controls. Foregoing changes of spatio-temporal parameters might be a predictor of fall risk, whereas foot pressure changes are related to risk of foot ulcers [18].

Sawacha et al. reveal reduction of trunk and lower limb joint mobility during walking in diabetes patients irrespective of neuropathy. Moreover, these alterations are more significant in patients with coexisting peripheral artery disease (PAD) [19]. Individuals with DM and PAD also walk more slowly [20]. Spatiotemporal parameters of gait are more affected in patients with DPN and neuropathic pain than in DPN with no pain, non-neuropathic DM patients, and healthy controls [21]. Older individuals with T2DM without overt DPN exhibit altered and less efficient gait patterns than non-diabetics people. These alterations are more apparent during walking at maximum speed [22] Alterations in spatio-temporal parameters of DPN patients' gait are in correlation with visual and vestibular information impairments, cognitive impairments, and muscle weakness [6].

People with DM exhibit changes in muscle activity. A few studies were performed to assess electromyographic activity of lower limb muscles in gait phases. A study by Savelberg et al. showed that independently of the preferred lower gait velocity, people with DM (with and without DPN) adjust the timing of muscle activity. They exhibit prolonged activity of monoarticular knee extensors and dorsal flexors of the foot. These findings suggest that alterations in muscle activity in DM may not depend only on the presence of neuropathy [23]. The same thesis was made by Sawacha et al. They assessed activity of lower limb muscles during walking in diabetes individuals with DPN, non-neuropathic diabetes people, and healthy controls. The alteration in rectus femoris activity in both DM groups at initial contact and loading response phases was observed. During the midstance phase a delay of gastrocnemius activity was observed in non-neuropathic diabetes subjects. The delay of rectus femoris and gluteus medius activity in the terminal swing phase was also observed in this group. These results indicate that functional changes in lower limb muscles occur before changes in peripheral nerve function can be detected [24].

People with diabetes-related plantar foot ulcers exhibit great alterations in gait pattern when compared to diabetes individuals with no ulceration history and healthy controls. They present decreased plantar flexion, knee flexion, and pelvis obliquity. They also have significantly greater range of anteroposterior ground reaction force, significantly slower walking speed, and shorter step length [25]. Guldemond et al. assessed diabetes patients' plantar pressures while performing some daily activities: level walking, ramp and stair walking, turning into different settings, and while performing Up \& Go test (TUG). Level walking and ascending a ramp resulted in the highest forefoot peak pressure compared with other activities. Across all activities and plantar regions, peak pressures were lower for patients with neuropathy than for non-neuropathic individuals [26]. A systematic review with meta-analysis performed by Fernando et al. showed a great agreement that patients with DPN present elevated plantar pressures and occupy a longer duration of time in stance-phase during gait [27].
A few studies have assessed diabetes gait characteristics in non-level walking. Allet et al. investigated gait parameters in walking on three types of surfaces (tar, grass, and stones) in three groups of subjects: T2DM with DPN, T2DM without DPN, and healthy controls. Significant differences between DM subjects and healthy individuals were observed, but there were no differences between both DM groups. The authors suggest that walking in real life conditions reveals gait difficulties in patients with T2DM before neuropathy is clinically detectable [28]. When negotiating the stairs, patients with DM, particularly those with DPN, walk more slowly than healthy controls. They also exhibit lower lower-limb muscular capabilities and lower knee joint moments [29]. Hsu et al. assessed obstacle-crossing ability during walking in diabetes patients without DPN or mild DPN, and healthy individuals. Obstacle negotiation during gait is an inevitable part of daily activities, and difficulties in obstacle-crossing may lead to tripping and falls. People with DM exhibit significant alterations in the swinging leg: reduced trailing toe clearance, reduced knee flexion, and reduced hip adduction. The higher plantar flexors moments in the leading stance leg were also observed. These results confirm the thesis that alterations in gait in DM may occur before clinical symptoms of neuropathy are present [30].

There is an agreement that walking strategies in people with DM are altered, especially those with DPN. Some studies suggest that changes in biomechanical parameters of diabetic gait are not directly related to DPN, because those changes are also detectable in non-neuropathic diabetes patients.

\section{Discussion}

Alterations in postural control and gait parameters in people with DM have confirmation in the literature $[8,18]$. Actually, all these data relate to adult subjects, most of them in old age and with a long history of the disease. Investigating the literature, we have found only one study focused on postural control in young adults with T1DM [17], and no studies on the gait characteristics, muscle function, and postural/motor control in children and adolescents with diabetes.

The changes in postural control and gait pattern are especially detectable in subjects with clinical DPN [10]. These patients exhibit deficits in sensorimotor function, balance, and gait $[8,38]$, their ability to maintain posture is affected [10-12], and they are at higher risk of falls [13] and foot ulcers [18, 27].

The prevalence of DPN is thought to be around $50 \%$ and increases with longer duration of the disease and poor glycaemic control [31]. In T1DM it is the major chronic complication, although its clinical manifestation typically occurs in adulthood [32]. Clinical symptoms of DPN are rarely seen in children with T1DM, but there is evidence that pathogenesis and early signs can develop during childhood and accelerate during puberty [3]. The American Diabetes Association recommends screening for DPN starting at five years after the diagnosis of T1DM and at least annually thereafter, with a nerve conduction study (NCS) as the gold standard [33]. On the other hand, 
there is evidence that clinical symptoms of neuropathy may occur earlier than five years after T1DM onset [34].

Typical DPN features sensory and motor dysfunction that progress in a distal to proximal, or length-dependent, manner [35]. DPN affects motor function, but significant motor deficits are not common in the early stages of the disease [36]. Numerous studies suggest that the most impactful consequence of DPN on the neuromuscular system is the accelerated loss of motor axons or motor units (MU), which is associated with neurogenic muscle atrophy and probably occurs later in the disease process, following sensory deficits [35]. On the other hand, Toth et al. suggested that MU loss begins in the early stage of the disease in children with T1DM, before their detection in standard electrophysiological examination is possible [37]. The best non-invasive method for studying functionality of motor nerve fibres and their innervated muscle fibres is Motor Unit Number Estimation (MUNE) - a technique performed using EMG [38]. Reduction of MUNE in T1DM children was observed in extensor digitorum brevis of lower limb when compared with healthy age-matched controls [37]. Moreover, participants of this study had no clinical or standard electrophysiological signs of neuropathy. The progressive loss of MUs is associated with the development of muscle weakness and atrophy $[35,39]$. Electromyographic evaluation also shows lower motor unit discharge frequencies (MUDF) and slower conduction velocities in knee extensors in young adults with T1DM when compared with healthy controls. It apparently leads to impaired activation of muscle and decreased endurance during isometric fatigue [40].

We found only two reports on dynamic muscle function in adolescents with T1DM. Frick et al. reported reduction in peak jump power assessed by jumping mechanography in correlation with glycaemic control [41]. The same method of muscle

\section{References}

1. Cameron FJ, Wherrett DK. Care of diabetes in children and adolescents: controversies, changes, and consensus. Lancet 2015; 23 : 2096-2106. doi: 10.1016/S0140-6736(15)60971-0

2. American Diabetes Association: Diagnosis and classification of diabetes mellitus. Diabetes Care 2010; 33 (Suppl 1): S62-69. doi: 10.2337/dc10-S062

3. Marcovecchio ML, Chiarelli F. Microvascular disease in children and adolescents with type 1 diabetes and obesity. Pediatr Nephrol 2011; 26: 365-375. doi: 10.1007/s00467-010-1624-9

4. Trotta D, Verrotti A, Salladini C, Chiarelli F. Diabetic neuropathy in children and adolescents. Pediatr Diabetes 2004; 5: 44-57. doi: 10.1111/j.1399-543X.2004.00041.x

5. Wong E, Backholer K, Gearon E, et al. Diabetes and risk of physical disability in adults: a systematic review and meta-analysis. Lancet Diabetes Endocrinol 2013; 1: 106-114. doi: 10.1016/S22138587(13)70046-9

6. Mustapa A, Justine M, Mustafah NM, et al. Postural control and gait performance in the diabetic peripheral neuropathy: a system- force assessment was used by Maratova et al. They revealed alterations in muscle function in adolescents with T1DM, especially those with disease duration longer than nine years. They also suggested that those alterations may contribute to the development of osteoporosis reported in adults with DM [42].

We can assume that the decrease in neuromuscular function in DM is in close correlation with gait performance and postural control alterations. The literature provides some evidence for such changes in diabetes patients; nevertheless, they have been described in the adult population. Evidence for loss of motor fibre function in children with T1DM supports the opinion that neuromuscular-related postural and motoric alterations might occur in this population. Evaluation of neuromuscular parameters of gait, posture, and muscle function potentially provide information on neuromuscular status in the early stages of T1DM. Early functional evaluation of the neuromuscular system in children with T1DM potentially facilitates detection of the onset of diabetes-related changes in the peripheral nervous system and correlates them with disease onset and duration. Early detection of these alterations should enable the implementation of preventive procedures.

\section{Conclusions}

Alterations in postural control, gait pattern, and muscle function exist in adult individuals with DM. There is no evidence on this topic regarding children and adolescents with T1DM. The nature and onset of these alterations remain unclear; neuropathic and non-neuropathic factors are suggested. We postulate the need for early assessment of neuromuscular function in children and adolescents with T1DM to identify the status of the neuromuscular system in this group of patients.

atic review. Biomed Res Int 2016; 2016: 9305025. doi: 10.1155/ 2016/9305025

7. Vervoort G, Bengevoord A, Strouwen C, et al. Progression of postural control and gait deficits in Parkinson's disease and freezing of gait: a longitudinal study. Parkinsonism Relat Disord 2016; 28 : 73-79. doi: 10.1016/j.parkreldis.2016.04.029

8. Bonnet C, Carello C, Turvey MT. Diabetes and postural stability: review and hypotheses. J Mot Behav 2009; 41: 172-190. doi: 10.3200/JMBR.41.2.172-192

9. Lin SI, Chen YR, Liao CF, et al. Association between sensorimotor function and forward reach in patients with diabetes. Gait Posture 2010; 32: 581-585. doi: 10.1016/j. gaitpost.2010.08.006

10. Yamamoto R, Kinoshita T, Momoki T, et al. Postural sway and diabetic peripheral neuropathy. Diabetes Res Clin Pract 2001; 52: 213-221.

11. Cimbiz A, Cakir O. Evaluation of balance and physical fitness in diabetic neuropathic patients. J Diabetes Complications 2005; 19 : 160-164. doi: 10.1016/j.jdiacomp.2004.06.005

12. Lafond D, Corriveau H, Prince F. Postural control mechanisms during quiet standing in patients with diabetic sensory neuropathy. Diabetes Care 2004; 27: 173-178. 
13. Brown SJ, Handsaker JC, Bowling FL, et al. Diabetic peripheral neuropathy compromises balance during daily activities. Diabetes Care 2015; 38: 1116-1122. doi: 10.2337/dc14-1982

14. Bonnet CT, Ray C. Peripheral neuropathy may not be the only fundamental reason explaining increased sway in diabetic individuals. Clin Biomech (Bristol, Avon) 2011; 26: 699-706. doi: 10.1016/j.clinbiomech.2011.03.004

15. Centomo H, Termoz N, Savoie S, et al. Postural control following a self-initiated reaching task in type 2 diabetic patients and agematched controls. Gait Posture 2007; 25: 509-514. doi: 10.1016/j. gaitpost.2006.06.010

16. Fulk GD, Robinson CJ, Mondal S, et al. The effects of diabetes and/or peripheral neuropathy in detecting short postural perturbations in mature adults. J Neuroeng Rehabil 2010; 7: 44. doi: 10.1186/1743-0003-7-44

17. Saka T, Yildiz Y, Deniz F, et al. Postural stability and functional capacity in recreational athletes with type 1 diabetes mellitus. Turk J Med Sci 2009; 39: 91-96.

18. Allet L, Armand S, Golay A, et al. Gait characteristics of diabetic patients: a systematic review. Diabetes Metab Res Rev 2008; 24 : 173-191. doi: 10.1002/dmrr.809

19. Sawacha Z, Gabriella G, Cristoferi G, et al. Diabetic gait and posture abnormalities: a biomechanical investigation through three dimensional gait analysis. Clin Biomech (Bristol, Avon) 2009; 24: 722-728. doi: 10.1016/j.clinbiomech.2009.07.007

20. Cheung CL, Lam KS, Cheung BM. Diabetes is associated with increased risk of low lean mass and slow gait speed when peripheral artery disease is present. J Diabetes Complications 2016; 30: 306311. doi: 10.1016/j.jdiacomp.2015.11.015

21. Lalli P, Chan A, Garven A, et al. Increased gait variability in diabetes mellitus patients with neuropathic pain. J Diabetes Complications 2013; 27: 248-254. doi: 10.1016/j.jdiacomp.2012.10.013

22. Ko SU, Stenholm S, Chia CW, et al. Gait pattern alterations in older adults associated with type 2 diabetes in the absence of peripheral neuropathy - results from the Baltimore Longitudinal Study of Aging. Gait Posture 2011; 34: 548-552. doi: 10.1016/j.gaitpost.2011.07.014

23. Savelberg HH, Ilgin D, Angin S, et al. Prolonged activity of knee extensors and dorsal flexors is associated with adaptations in gait in diabetes and diabetic polyneuropathy. Clin Biomech (Bristol, Avon) 2010; 25: 468-475. doi: 10.1016/j.clinbiomech.2010.02.005

24. Sawacha Z, Spolaor F, Guarneri G, et al. Abnormal muscle activation during gait in diabetes patients with and without neuropathy. Gait Posture 2012; 35: 101-105. doi: 10.1016/j.gaitpost.2011.08.016

25. Fernando ME, Crowther RG, Lazzarini PA, et al. Gait parameters of people with diabetes-related neuropathic plantar foot ulcers. Clin Biomech (Bristol, Avon) 2016; 37: 98-107. doi: 10.1016/j.clinbiomech.2016.06.006

26. Guldemond NA, Leffers P, Sanders AP, et al. Daily-life activities and in-shoe forefoot plantar pressure in patients with diabetes. Diabetes Res Clin Pract 2007; 77: 203-209. doi: 10.1016/j.diabres.2006.11.006

27. Fernando M, Crowther R, Lazzarini P, et al. Biomechanical characteristics of peripheral diabetic neuropathy: a systematic review and meta-analysis of findings from the gait cycle, muscle activity and dynamic barefoot plantar pressure. Clin Biomech (Bristol, Avon) 2013; 28: 831-845. doi: 10.1016/j.clinbiomech.2013.08.004

28. Allet L, Armand S, de Bie RA, et al. Gait alterations of diabetic patients while walking on different surfaces. Gait Posture 2009; 29: 488-493. doi: 10.1016/j.gaitpost.2008.11.012

29. Brown SJ, Handsaker JC, Maganaris CN, et al. Altered joint moment strategy during stair walking in diabetes patients with and without peripheral neuropathy. Gait Posture 2016; 46: 188-193. doi: 10.1016/j.gaitpost.2016.03.007

30. Hsu WC, Liu MW, Lu TW. Biomechanical risk factors for tripping during obstacle-crossing with the trailing limb in patients with type II diabetes mellitus. Gait Posture 2016; 45: 103-109. doi: 10.1016/j. gaitpost.2016.01.010

31. Nathan DM. The diabetes control and complications trial/epidemiology of diabetes interventions and complications study at 30 years: overview. Diabetes Care 2014; 37: 9-16. doi: 10.2337/dc13-2112

32. Louraki M, Karayianni C, Kanaka-Gantenbein C, et al. Peripheral neuropathy in children with type 1 diabetes. Diabetes Metab 2012; 38: 281-289. doi: 10.1016/j.diabet.2012.02.006

33. American Diabetes Association: 10. Microvascular complications and foot care. Diabetes Care 2017; 40 (Suppl 1): S88-S98. doi: 10.2337/dc17-S013

34. Shafi OM, Latief M. Early onset symptomatic neuropathy in a child with type 1 diabetes mellitus. Diabetes Metab Syndr 2017; 11 (Suppl 1): S477-S479. doi: 10.1016/j.dsx.2017.03.039

35. Allen MD, Doherty TJ, Rice CL, Kimpinski K. Physiology in medicine: neuromuscular consequences of diabetic neuropathy. J Appl Physiol (1985) 2016; 121: 1-6. doi: 10.1152/japplphysiol.00733.2015

36. Tesfaye S, Selvarajah D. Advances in the epidemiology, pathogenesis and management of diabetic peripheral neuropathy. Diabetes Metab Res Rev 2012; 28 (Suppl 1): 8-14. doi: 10.1002/dmrr.2239

37. Toth C, Hebert V, Gougeon C, et al. Motor unit number estimations are smaller in children with type 1 diabetes mellitus: a case-cohort study. Muscle Nerve 2014; 50: 593-598. doi: 10.1002/mus.24212

38. Meltzer S, Leiter L, Daneman D, et al. 1998 clinical practice guidelines for the management of diabetes in Canada. Canadian Diabetes Association. CMAJ 1998; 159 (Suppl 8): S1-S29.

39. Allen MD, Major B, Kimpinski K, et al. Skeletal muscle morphology and contractile function in relation to muscle denervation in diabetic neuropathy. J Appl Physiol (1985) 2014; 116: 545-552. doi: 10.1152/japplphysiol.01139.2013

40. Almeida S, Riddell MC, Cafarelli E. Slower conduction velocity and motor unit discharge frequency are associated with muscle fatigue during isometric exercise in type 1 diabetes mellitus. Muscle Nerve 2008; 37: 231-240. doi: 10.1002/mus.20919

41. Fricke O, Seewi O, Semler O, et al. The influence of auxology and long-term glycemic control on muscle function in children and adolescents with type 1 diabetes mellitus. J Musculoskelet Neuronal Interact 2008; 8: 188-195.

42. Maratova K, Soucek O, Matyskova J, et al. Muscle functions and bone strength are impaired in adolescents with type 1 diabetes. Bone 2018; 106: 22-27. doi: 10.1016/j.bone.2017.10.005 